\title{
AS RECEPÇÕES DO MUNDO ANTIGO NA REVISTA HERÓDOTO
}

O presente número da Revista Heródoto apresenta um rico conjunto de contribuições organizado em três partes. A primeira é consagrada ao dossiê intitulado "Recepções da Antiguidade", organizado com a valiosa colaboração do professor Anderson Zalewski Vargas (UFRGS), que é composta por uma entrevista concedida à revista pelo professor Vargas e por um conjunto de oito artigos que tratam de processos variados de recepção da Antiguidade (a apresentação do dossiê é detalhadamente feita pelo professor Vargas no texto As recepções e as conformações de passado e presente).

A sessão "Artigos" é composta por um conjunto de três textos. O primeiro, de Eduardo Aubert, é a releitura de um fragmento de Píndaro acerca de uma passagem mitológica, a partir do qual discute-se a noção controle e violência. O segundo, de Pierre Mbid Hamoudi Diouf, discute procedimentos médicos na Antiguidade, a partir da leitura de obras de autores antigos e explorando exemplos do conhecimento médico, algumas práticas medicinais e cirúrgicas. O terceiro artigo, de Fernando Mattiolli Vieira, é um observação crítica do cenário de contribuições da Arqueologia (e seu diálogo com a História) para a interpretação dos Manuscritos de Qumran.

Este número também apresenta um conjunto de três resenhas de publicações recentes. Trata-se de visões gerais sobre diferentes objetos: o mundo cicládico, os vários processos e contextos de recepção da figura de Alexandre, o Grande e, ainda, uma observação autoral sobre a Mesopotâmia Antiga.

Por fim, temos o prazer de anunciar que, a partir deste número, a revista conta com um novo editor. Trata-se de Gustavo Junqueira Duarte Oliveira Junqueira, responsável pela seção de resenhas.

Desejamos a todas e todos uma excelente leitura.

Gilberto da Silva Francisco e Glaydson José da Silva Editores 